Document downloaded from:

http://hdl.handle.net/10251/149956

This paper must be cited as:

Torregrosa, AJ.; Broatch, A.; Olmeda, P.; Salvador-lborra, J.; Warey, A. (2017).

Experimental study of the influence of exhaust gas recirculation on heat transfer in the firedeck of a direct injection diesel engine. Energy Conversion and Management. 153:304312. https://doi.org/10.1016/j.enconman.2017.10.003

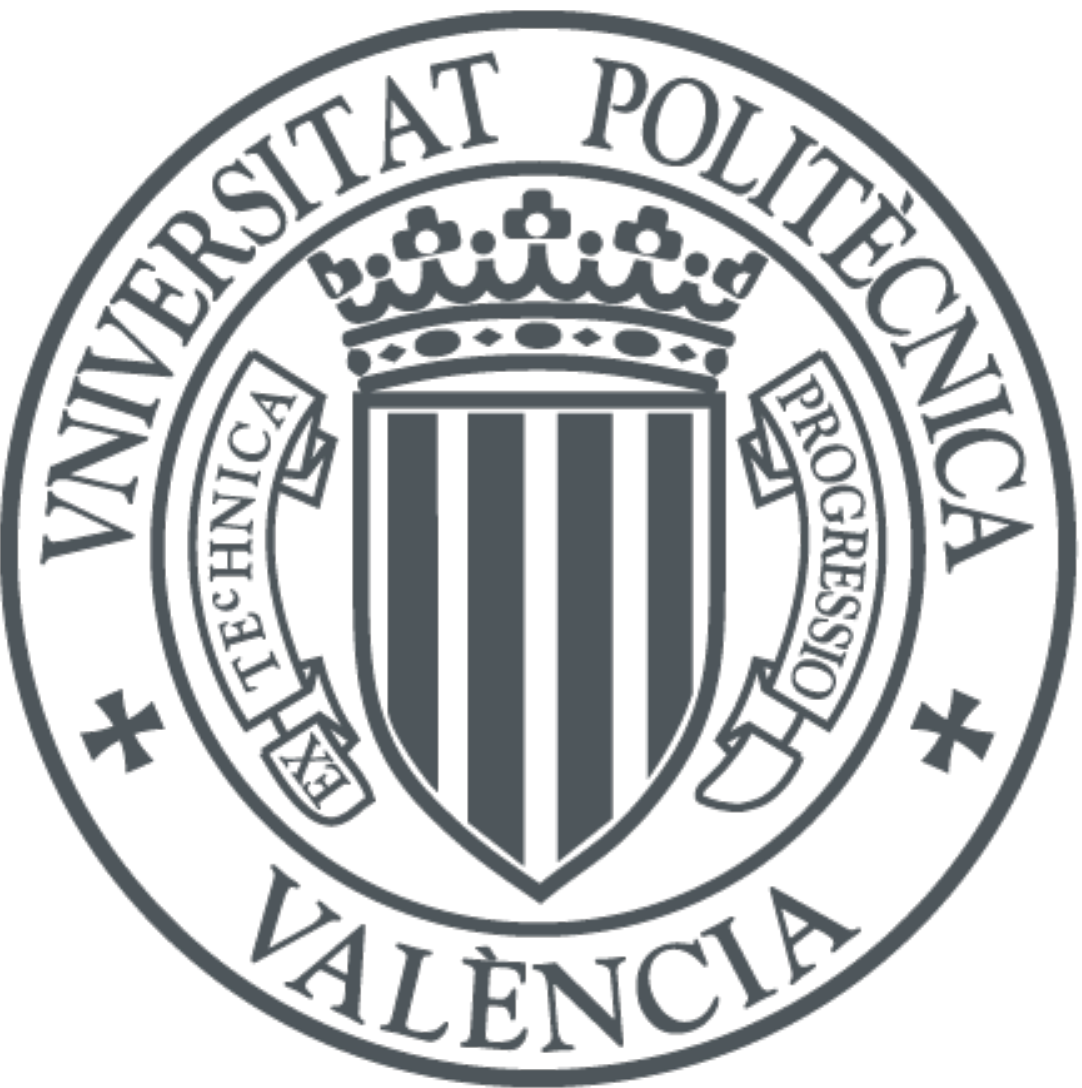

The final publication is available at

https://doi.org/10.1016/j.enconman.2017.10.003

Copyright Elsevier

Additional Information 


\title{
Experimental study of the influence of exhaust gas recirculation on heat transfer in the firedeck of a direct injection diesel engine
}

\author{
Antonio José Torregrosa ${ }^{a}$, Alberto Broatch $^{a}$, Pablo Olmeda $^{* a}$, \\ Josep Salvador-Iborra ${ }^{a}$, Alok Warey ${ }^{b}$ \\ ${ }^{a}$ CMT-Motores Térmicos, Universitat Politècnica de València, Camí de Vera s/n, \\ 46022 Valencia, Spain \\ ${ }^{b}$ Propulsion Systems Research Lab, General Motors Global Research and Devel- \\ opment, United States
}

\begin{abstract}
Emissions control is a key topic for internal combustion engine development. One of the most widespread technologies to reduce the formation of nitrogen oxides is the recirculation of exhaust gas to the engine intake. Besides, carbon dioxide emissions from internal combustion engines can be reduced by increasing engine efficiency. A relevant factor for engine efficiency is heat rejection. The interaction between heat transfer and exhaust gas recirculation is not fully understood. In this paper, an experimental study is presented which aims to shed light on the influence of high pressure exhaust gas recirculation on heat transfer. Three operating points were analyzed. Heat flux was calculated at several locations of the firedeck from temperature measurements. The results showed that the influence of exhaust gas recirculation on heat transfer was significant. Reductions of heat flux up to $18 \%$ were observed. The largest reduction was found in the area near the center of the firedeck. To contextualize the findings in the framework of emissions reduction, the trade-off between nitrogen oxides and carbon dioxide was assessed for all test points.
\end{abstract}

Keywords: EGR, heat transfer, $\mathrm{CO}_{2}$, wall temperature, thermocouple

\section{Introduction}

Engine research activities are aimed at reducing pollutant emissions [1]. Internal combustion engines generate nitrogen oxides $\left(\mathrm{NO}_{x}\right)$, carbon monoxide $(\mathrm{CO})$ and hydrocarbons (HC) [2]. In addition, greenhouse gas emissions have become an increasing

\footnotetext{
Abbreviations: aTDC, after TDC; BMEP, break mean effective pressure; CA50, crank angle where $50 \%$ of total heat is released; $\mathrm{CC}$, combustion chamber; $\mathrm{CO}_{2}$, carbon dioxide; $\Delta$, increment; EGR, exhaust gas recirculation; FSN, filter smoke number; IVC, intake valve closing; $\mathrm{NO}_{x}$, nitrogen oxides; q, heat flux density; RTD, resistance temperature detector; SR, swirl ratio; T, temperature; TC, thermocouple; TDC, top dead center; VGT, variable geometry turbine.

* Corresponding author. Tel.: +34 963877650 .

E-mail address: pabolgon@mot.upv.es (P. Olmeda).
} 
concern in recent years [3]. One of the most relevant greenhouse gases, carbon dioxide $\left(\mathrm{CO}_{2}\right)$, is produced in engines as a result of fuel combustion [4]. Therefore, regulators are imposing restrictions on $\mathrm{CO}_{2}$ emitted by engines [5]. Several strategies can be applied to reduce fuel consumption and thus diminish $\mathrm{CO}_{2}$ emissions. One of them is to improve engine efficiency, which can in turn be achieved by different ways. Reducing heat losses during the thermodynamic cycle contributes to increase engine indicated efficiency. If heat loss is reduced, more energy remains inside the combustion chamber. Part of this extra energy is converted into additional mechanical work. The higher the indicated efficiency, the lower the fuel consumption and thereby the $\mathrm{CO}_{2}$ emissions. Apart from in-cylinder heat losses, heat transfer is important in engines for other reasons. Temperatures in the engine, exhaust energy recovery and intake process performance are other aspects affected by heat transfer [6].

The present paper is focused on the interaction of in-cylinder heat transfer and exhaust gas recirculation (EGR). EGR is a technique to control the formation of nitrogen oxides [7]. Nitrogen oxides are a family of pollutants associated with respiratory and cardiovascular diseases [8]. They are formed in the presence of oxygen and nitrogen at conditions of high temperature [9]. The environment that exists in the cylinder of compression ignition engines specifically favors $\mathrm{NO}_{x}$ formation. Compression ignition engines operate at higher compression ratios to achieve higher pressures and temperatures for auto-ignition. Excess air is also a contributing factor due to higher air-fuel ratios, particularly at partial load [10]. When the EGR system is active, part of the exhaust flow is circulated to the engine intake to mix with the fresh charge and enter the cylinder again. The resulting mixture has a lower oxygen concentration and higher heat capacity than the fresh air [11] and it contains inert gases that do not burn during the combustion phase [12]. As a consequence, peak temperatures in the cylinder are lower [13]. Moreover, the lower concentration of oxygen also hinders $\mathrm{NO}_{x}$ formation [14]. Those alterations of the combustion chamber conditions promote a large reduction of $\mathrm{NO}_{x}$ emissions but also have some drawbacks. Thermal efficiency may diminish because the lower oxygen concentration can hinder the combustion process [15]. Depending on the method to recirculate the exhaust gas, pumping or ancillary losses may increase significantly [16]. Efficiency deterioration involves higher fuel consumption and $\mathrm{CO}_{2}$ production [17]. Emissions of particulate matter and carbon monoxide tend to increase [18]. In addition, intake ports and lubricating oil get polluted by the recirculated gas [19].

Several studies related to EGR can be found in the literature. Ladommnatos conducted a series of systematic experiments [20] to assess the different effects of EGR (dilution, chemical, and thermal) on $\mathrm{NO}_{x}$ generation in an isolated manner. He found that the dilution effect (replacement of the inlet oxygen by exhaust gases) was the most significant factor [21]. EGR plays an important role in new combustion concepts such as Stoichiometric Diesel Combustion [22] or Low-Temperature Combustion [23]. In Stoichiometric Diesel Combustion, the dilution effect of EGR is used to reach the stoichiometric air-fuel ratio so that a cost effective Three Way Catalyst can be employed to reduce gaseous emissions [24]. Simultaneously, fuel savings up to $10 \%$ have been reported [25]. Low Temperature Combustion is another promising solution to reduce fuel consumption and prevent the formation of $\mathrm{NO}_{x}$ and soot [26]. Under that combustion mode, EGR contributes to reduce combustion temperature [27] and extend the ignition delay [28].

Since EGR alters in-cylinder conditions and energy release, it is interesting to as- 
sess the effects not only on the target pollutant formation but also on performance indicators such as heat transfer. With regard to the influence of EGR on in-cylinder heat transfer, precedents are scarce and discordant. Finol [29] measured wall temperatures at different locations and depths along a cylinder liner using a technique similar to the one used in the present work. Results showed slight variations in heat flux and negligible differences in wall temperatures. Caton [30] observed increases of in-cylinder heat transfer and the convective heat transfer coefficient with EGR. Recently, a research about the impact of EGR on the different terms of the global energy balance of a diesel engine was published [31]. Experimentally, heat rejection to coolant and oil were observed to increase with EGR. To gain more insight, the in-cylinder pressure trace and mean fluid temperatures were entered as inputs of an in-house thermodynamic model [32] with a heat transfer submodel [33]. According to the model, heat rejection to the firedeck barely changed with EGR. Moreover, incylinder heat transfer decreased during the closed cycle and increased during the open cycle, likely due to the EGR effect on gas temperature. Those diverse trends motivated an experimental investigation of in-cylinder heat transfer. In summary, the effect of EGR on heat transfer is under discussion. Different authors reported that EGR increased, decreased or had no effect on in-cylinder heat transfer. Regarding heat rejection to the cylinder-head and material temperature, the literature suggests that EGR has a negligible effect on them. An experimental approach to this problem is suitable because it avoids hypotheses assumed by models.

The objective of this study was to assess experimentally the impact of high pressure EGR on heat transfer and the repercussion on emissions. The selected method to measure heat flux was based on the installation of thermocouples in the firedeck wall. This allowed to measure mean wall temperatures in different locations of the firedeck. Various levels of EGR rate at different engine operating conditions were tested. The thermocouples were arranged in pairs. Conductive heat flux was calculated for each pair of thermocouples and analyzed. The spatial distribution of axial heat flux over two sections of the firedeck was obtained. Lastly, an evaluation of the trade-off between $\mathrm{NO}_{x}$ and $\mathrm{CO}_{2}$ for all the measured points was made.

\section{Experimental test facility}

A four-cylinder, four-stroke engine was used to carry out the experimental tests. The engine was equipped with a high pressure exhaust gas recirculation system and a variable geometry turbocharger (VGT). Engine specifications are given in Table 1. The engine hardware is representative of EURO IV emissions regulations.

Table 1: Engine specifications.

\begin{tabular}{ll}
\hline Bore & $82 \mathrm{~mm}$ \\
Stroke & $90.4 \mathrm{~mm}$ \\
Displaced volume & 1.9 liter \\
Compression ratio & $17.5: 1$ \\
Maximum power & $110 \mathrm{~kW}(4000 \mathrm{rpm})$ \\
\hline
\end{tabular}

Main engine instrumentation is listed in Table 2. EGR rate was measured with 
an emissions analyzer. An opacimeter was employed to determine soot concentration. Fluid temperatures were measured with K-type thermocouples and PT100 resistance temperature detectors. An electric dynamometer was used to set engine speed and measure torque. All those signals plus others such as air and fuel mass flows were monitored and recorded with an in-house engine control system. A Drivven control module allowed setting parameters such as injection timing and duration, turbine configuration or position of EGR and swirl valves.

Table 2: Test cell instrumentation.

\begin{tabular}{|c|c|c|c|}
\hline Variable & Sensor & Range & Accuracy \\
\hline $\mathrm{CO}_{2}$ concentration & Horiba MEX & 1-10 $\quad 0-20$ vol\% & $4 \%$ \\
\hline Opacity & Opacimeter AVL 390 & $0-100 \%$ & $0.01 \%$ \\
\hline Temperature of gases & rmocouples & -200 to $1250{ }^{\circ} \mathrm{C}$ & $0.1^{\circ} \mathrm{C}$ \\
\hline Temperature of liquids & RTD (PT100) & -30 to $350{ }^{\circ} \mathrm{C}$ & $0.01^{\circ} \mathrm{C}$ \\
\hline Torque & Dynamometer & $0-500 \mathrm{Nm}$ & $0.5 \%$ \\
\hline Air mass flow & AVL Flowsonix Air & $0-1400 \mathrm{~kg} / \mathrm{h}$ & $1 \%$ \\
\hline Fuel mass flow & AVL 733S & $0-41.67 \mathrm{~g} / \mathrm{s}$ & $0.12 \%$ \\
\hline
\end{tabular}

\subsection{Instrumentation for wall temperature measurement}

The firedeck was instrumented with slow-response K-type thermocouples that were inserted through holes drilled directly in the cylinder head. In the firedeck under study there were 17 thermocouples distributed on two planes perpendicular to the cylinder axis. First section was located $4 \mathrm{~mm}$ above the combustion chamber surface and second section was at $7 \mathrm{~mm}$ above the surface. Measurement locations of thermocouples are represented in Figure 1. Piston bowl location and fuel spray directions are also indicated in the figure. Since both planes had the same thermocouples distribution, they were arranged in couples separated $3 \mathrm{~mm}$ from each other -except one of them on the exhaust side- as can be seen in Figure 1. Thus, there were 8 pairs of thermocouples and one thermocouple located $4 \mathrm{~mm}$ above the surface which was single. To study axial heat transfer, a thermocouple installation was preferred over heat flux probes because it permitted a higher flexibility of the drill direction. That was essential considering the complex internal geometry of a production engine and the hard-to-reach areas to be instrumented. In addition, heat flux sensors would cause higher disturbances in the temperature field [6]. In order to reduce temperature measurement errors with thermocouples, the following precautions were taken:

- The inserted length of the thermocouple into the material was, at least, 5 times the thermocouple diameter.

- The shape of the bottom of the hole matched the shape of the end of the sensor and the sensor was pressed fully to the bottom.

\section{Methods}

In this section, the procedures used in the experiment and the data analysis are presented. First subsection reports the test campaign. Next, the method to obtain heat 


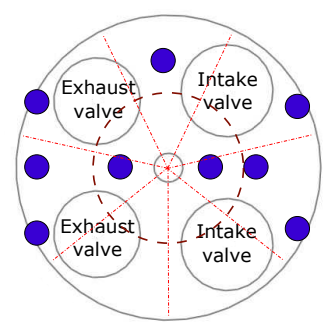

(a) Section $4 \mathrm{~mm}$ above $\mathrm{CC}$

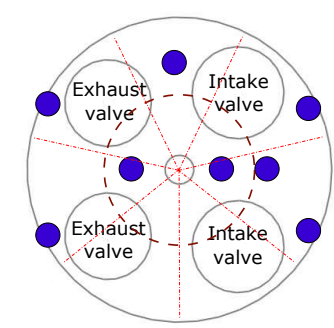

(b) Section $7 \mathrm{~mm}$ above $\mathrm{CC}$

Figure 1: Thermocouple distribution in firedeck

flux is explained. In the last subsection, the maps used to display spatial information are described.

\subsection{Test procedure}

Three different engine operating points were analyzed. For every operating point, the maximum EGR rate was determined by finding the EGR valve position that fulfilled the condition of maximum soot concentration $(\mathrm{FSN}=3)$. Minimum EGR rate was always $0 \%$. EGR valve was operated to obtain a third EGR rate value, stable and as close as possible to the average between the maximum and the minimum. Tested EGR rates for each operating point can be consulted in Table 3. Two levels of swirl ratio $(\mathrm{SR}=1.4$ and 3$)$ were studied for each EGR sweep. Those values were the minimum and the maximum swirl ratios that could be achieved with the swirl flap in the ports.

The initial test was done under conditions of maximum EGR rate. First, the electric dynamometer coupled to the engine was operated to fix engine speed at the target value. The variable geometry turbine was positioned in the configuration that maximized the intake pressure. Swirl valve was completely closed $(\mathrm{SR}=3)$ which obstructed the intake flow. Main injection timing was set in order to keep CA50 at 13 degrees after TDC. Main injection duration was set in order to reach the nominal torque (and BMEP) for each operating point. Under those conditions, intake mass flow and fuel consumption were measured. Their values were maintained during the EGR and swirl sweep for each operating point. Torque, in contrast, changed in response to the variations of the other parameters. In the high pressure EGR system, when the EGR valve was closed, higher exhaust gas flow was directed to the turbine and so the turbocharger had more energy to boost intake pressure. To keep the same intake mass flow, the turbine configuration had to be adjusted in order to compensate for the increase in intake pressure. Likewise, when swirl valve was completely open $(\mathrm{SR}=1.4)$ head loss in the intake ports was lower and the turbocharger had to provide a lower intake pressure to maintain intake mass flow. Intake charge temperature was fixed at $45^{\circ} \mathrm{C}$ by PID controllers that regulated the coolant flows through the intercooler and the EGR cooler. In that manner, conditions at intake valve closure were kept constant and thus volumetric efficiency was assumed to be equal. Injection duration was slightly adjusted in order to keep constant the fuel mass flow. In addition, dwell and mass of pilot injections were the same for all tests. Lastly, PID controllers maintained coolant 
and oil temperatures at $87^{\circ} \mathrm{C}$ and $95^{\circ} \mathrm{C}$ respectively. Those temperature values are found in typical engines during normal operation. The stabilization time was between 20 and 40 minutes for each measured point. This procedure was devised to allow for a back-to-back comparison among all measurements. A diagram of the procedure is shown in figure 2 .
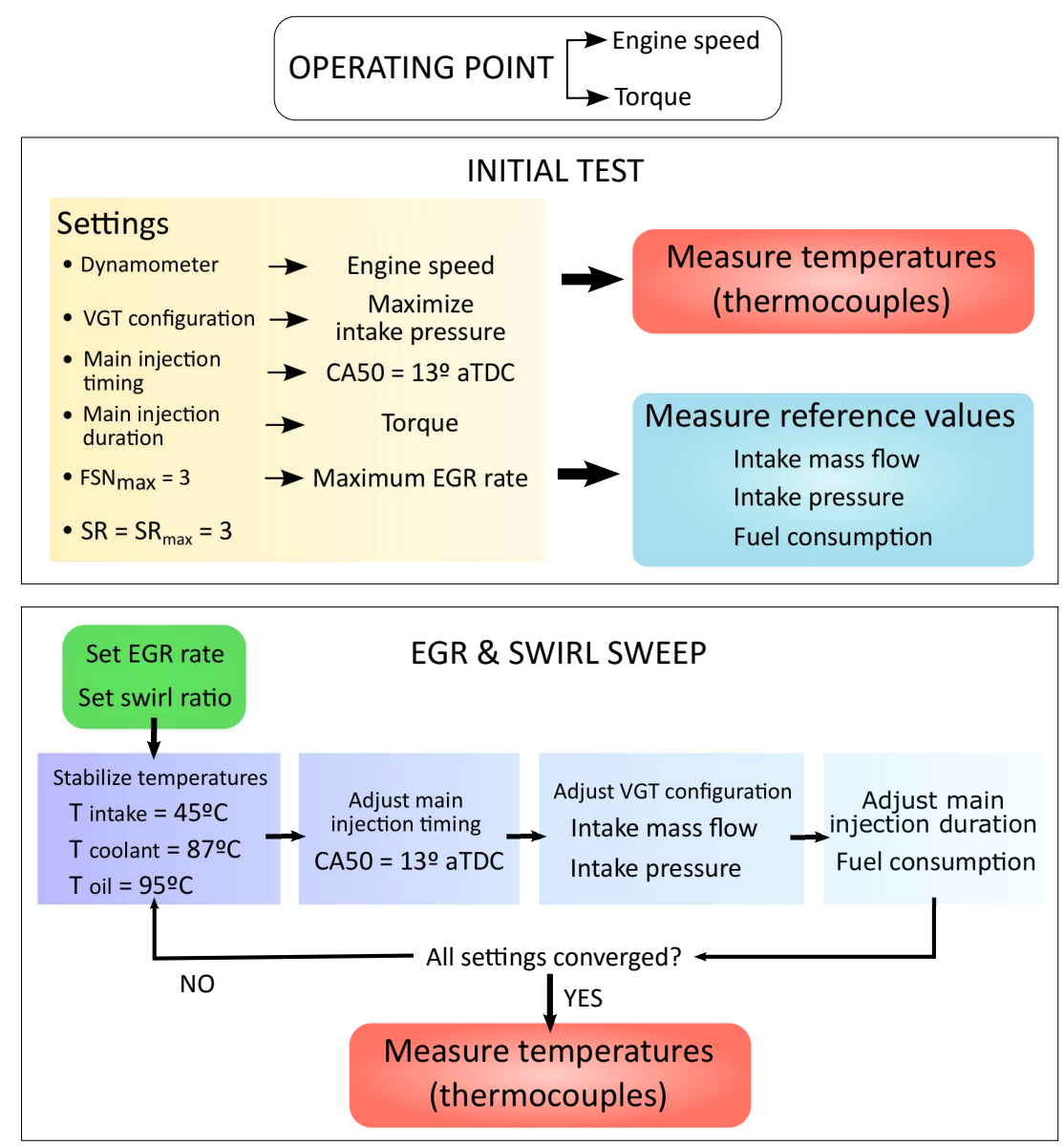

Figure 2: Experimental procedure.

For every operating condition, three repetitions were measured and averaged. In each repetition, thermocouple measurements were scanned every four seconds for one minute. Response time of thermocouples was below 2 seconds. Scans were then averaged for each thermocouple and repetition. Altogether, 54 measurements of 18 different operating conditions were collected from each thermocouple.

Engine operating points were selected for being representative of typical engine operating conditions. Engine speed for two of the operating points was $2000 \mathrm{rpm}$, while load was 10\% (2 bar BMEP) and 24\% (5 bar BMEP), respectively. Third point had intermediate values of load (48\%, 8 bar BMEP) and engine speed (1500 rpm). To refer to engine operating points, the format [Engine speed in rpm] @ [BMEP in bar] 
was used, e.g. 2000@2 is the operating point with engine speed $2000 \mathrm{rpm}$ and 2 bar BMEP.

Table 3: Operating points and EGR rates.

\begin{tabular}{cccc}
\hline Operating point & \multicolumn{3}{|c}{ EGR rate (\%) } \\
\hline 2000@2 & 0 & 15 & 30 \\
2000@5 & 0 & 12.5 & 25 \\
$1500 @ 8$ & 0 & 4 & 12 \\
\hline
\end{tabular}

\subsection{Heat flux calculation}

Heat flux was calculated from temperature measurements. 8 pairs of thermocouples were located on two sections separated $3 \mathrm{~mm}$ from each other. That configuration allowed calculating axial flux from the temperature difference between both planes, for every thermocouple pair. Conductivity was assumed homogeneous and equal to $0.144 \mathrm{kWm}^{-1} \mathrm{~K}^{-1}$ considering that the cylinder-head was made of an aluminum alloy [34]. Equation 1 was used to calculate heat flux per unit area.

$$
q=\frac{Q}{A}=k \frac{T(4 m m)-T(7 m m)}{0.003 m} \quad\left[k W m^{-2}\right]
$$

where $Q$ is the axial component of heat flux in $k W, \mathrm{~A}$ is contact area in $m^{2}, \mathrm{k}$ is thermal conductivity in $k W m^{-1} K^{-1}$ and $\mathrm{T}$ is temperature in $K$.

Standard deviation was used to evaluate the uncertainty of the temperature measurement. Three repetitions of every experimental point were measured. The standard deviation among the repetitions varied between $0.01^{\circ} \mathrm{C}$ and $0.1^{\circ} \mathrm{C}$. Consequently, the number of repetitions was enough to obtain a dispersion lower than the measurement error of the thermocouples. According to equation 1 , an uncertainty of $\left(\Delta \mathrm{T} \pm 0.2^{\circ} \mathrm{C}\right)$ yields an uncertainty in heat flux of $9.6 \mathrm{kWm}^{-2}$.

\subsection{Distribution map}

Bi-dimensional fields were calculated by means of linear interpolation and extrapolation from the data obtained in the measurement locations. Those maps were used to represent the spatial distribution of temperature variation and heat flux variation. An example is provided in Figure 3, where the field of the axial heat flux per unit area in the firedeck is represented. Locations of thermocouple pairs are marked with a black dot. At those locations, heat flux was calculated using the method described in section 3.2. Operating point for the map is $2000 @ 5$, with maximum swirl ratio and no EGR.

\section{Results and discussion}

Discussion of results is divided in three parts. Since wall temperatures were the measured variables, first analysis is focused on the effect of EGR on those temperatures. Once the effects on wall temperatures are explained, the influence of EGR on heat flux is discussed. Finally, to contextualize the findings in the general research endeavor to reduce pollution, the impact of those effects on the engine-out emissions is assessed. 


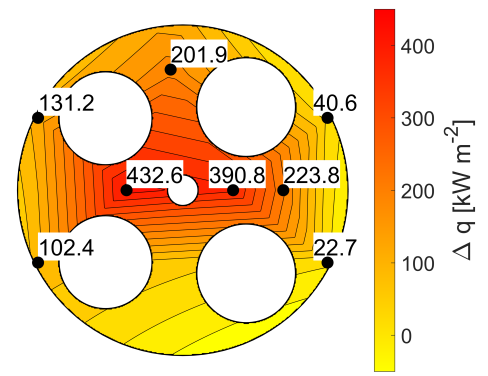

Figure 3: 2000@5 Axial heat flux field in the firedeck. SR = 3, no EGR.

\subsection{Influence of exhaust gas recirculation on wall temper- ature}

In Figure 4, temperature variation given by equation 2 was plotted for all measurement locations and then the procedure explained in section 3.3 was applied to obtain distribution maps.

$$
\Delta T_{i}=T_{i}\left(\mathrm{EGR}_{\max }\right)-T_{i}\left(\mathrm{EGR}_{\min }\right) \quad\left[{ }^{\circ} \mathrm{C}\right]
$$

where $i$ is the operating point: $\mathrm{i}=2000 @ 5,2000 @ 2$, 1500@8. All maps of Figure 4 refer to the plane $4 \mathrm{~mm}$ above the surface of the firedeck.

In Figure 4(a) two effects can be observed. In most of the firedeck, EGR decreased wall temperature. That is due to the fact that mean chamber gas temperature decreases with EGR, as was mentioned earlier. Impact was higher near the center of the firedeck, where coolant channels are further and temperatures of the solid are more sensitive to changes in in-cylinder conditions than in outer areas closer to coolant streams. Furthermore, the measuring location where the temperature drop was highest (close to the center on the intake side) was the one that received the weakest influence from coolant because galleries were bigger on the exhaust side than on the intake side. The second effect was the small temperature increase on the left side of the map, close to the exhaust ports. A possible reason for that behavior is that the presence of combustion products increases ignition delay and shifts the combustion process towards the expansion stroke [35]. Therefore, temperature of exhaust gas is higher with EGR [31] and the area around the exhaust ports receives more heat. That behavior near the exhaust ports was not noticed clearly in the low load point 2000@2 when swirl ratio was low (see Figure 4(d)). However, it could be observed with high swirl ratio in Figure 4(c). Going into more depth, it is possible to notice that, in each operating point, the temperature increment of the three thermocouples on the left side of the firedeck is always higher when high swirl is present (left side plots, 4(a), 4(c) and 4(e)) than with low swirl (right side plots, 4(b), 4(d) and 4(f)). A possible explanation to this behavior is that, with higher swirl, the flame cannot reach the regions close to the liner. Another possibility is that swirl intensifies the combustion broadening previously mentioned. However, without additional data, those hypotheses cannot be confirmed. Optical data obtainable with in-cylinder probes or optical engines could provide the necessary information to clarify this matter. 


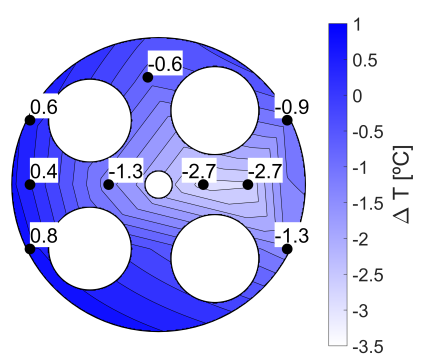

(a) 2000@5, high swirl

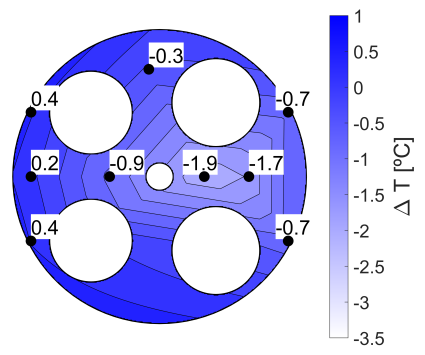

(c) 2000@2, high swirl

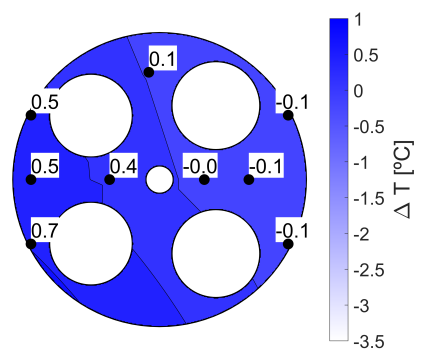

(e) 1500@8, high swirl

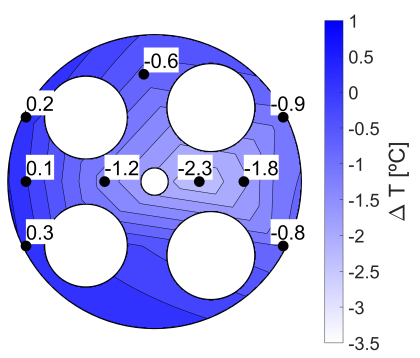

(b) 2000@5, low swirl

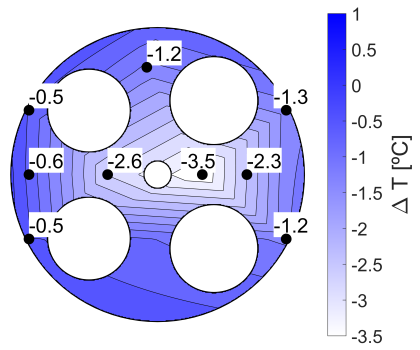

(d) 2000@2, low swirl

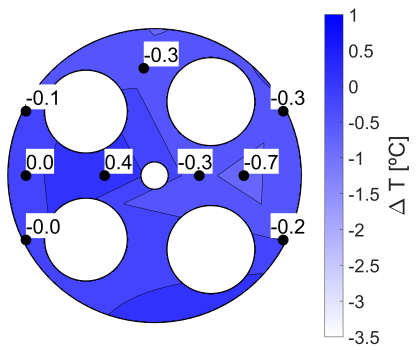

(f) $1500 @ 8$, low swirl

Figure 4: Local distribution of the EGR effect on wall temperatures 
Operating point 1500@8 did not present a clear influence of EGR (see Figures 4(e) and $4(\mathrm{f}))$. At this operating point, the soot limit of FSN $=3$ was reached at an EGR rate of $12 \%$, which was lower compared to the other operating points used in this study.

Figure 5 shows a comparison between both thermocouple planes, located $4 \mathrm{~mm}$ and $7 \mathrm{~mm}$ above the combustion chamber, respectively. Once again, the temperature difference calculated with equation 2 was plotted. Operating point was 2000@5 and swirl was low. Spatial distribution of EGR effect on the upper plane was similar to that of the lower plane and its magnitude was lower or similar.

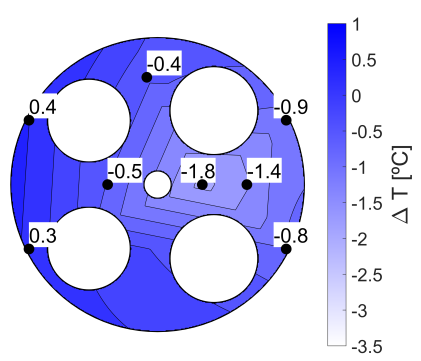

(a) Plane $7 \mathrm{~mm}$ above $\mathrm{CC}$

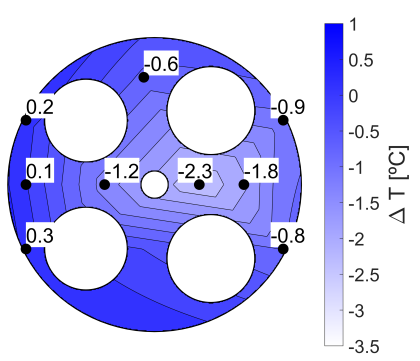

(b) Plane $4 \mathrm{~mm}$ above $\mathrm{CC}$

Figure 5: Comparison between planes of the EGR effect on wall temperatures

Temperature variations caused by EGR were up to $4^{\circ} \mathrm{C}$ in all measurement locations on both planes and all operating points. After the literature survey (references [29], [31]), a non-significant effect of EGR was expected. However, the present study showed that EGR had a significant influence on wall temperatures. That was true for operating points 2000@2 and 2000@5. Spatial trends were consistent among the tests. It must be noted that the effect of EGR was sharper in the center of the firedeck.

\subsection{Impact of exhaust gas recirculation on heat transfer}

To study heat transfer, axial heat flux per unit area was calculated using the procedure explained in section 3.2. First matter to be investigated was the magnitude of the change in heat transfer caused by EGR. That allowed to assess the relevance of EGR as an influencing factor in heat transfer. To analyze that, data from the four thermocouple pairs located closest to the center was used. They are marked in Figure 6. Those thermocouples were chosen because in those areas the variations of heat flux were generally larger than the uncertainty value calculated in section 3.2. This ensured the significance of the observed effects. In Figure 7, the variation of heat flux induced by EGR as a percentage is shown. For each operating point, there are four columns corresponding to the four thermocouple pairs under study. EGR rate is the maximum of each operating point, while swirl level is the lowest. Equation 3 was applied to obtain the plotted magnitude.

$$
\Delta q_{i}=\frac{q_{i}\left(\mathrm{EGR}_{\max }\right)-q_{i}\left(\mathrm{EGR}_{\text {min }}\right)}{q_{i}\left(\mathrm{EGR}_{\text {min }}\right)} 100 \quad[\%]
$$




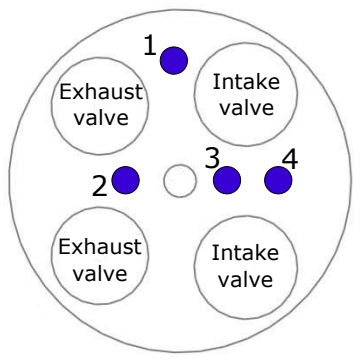

Figure 6: Measurement locations closest to center

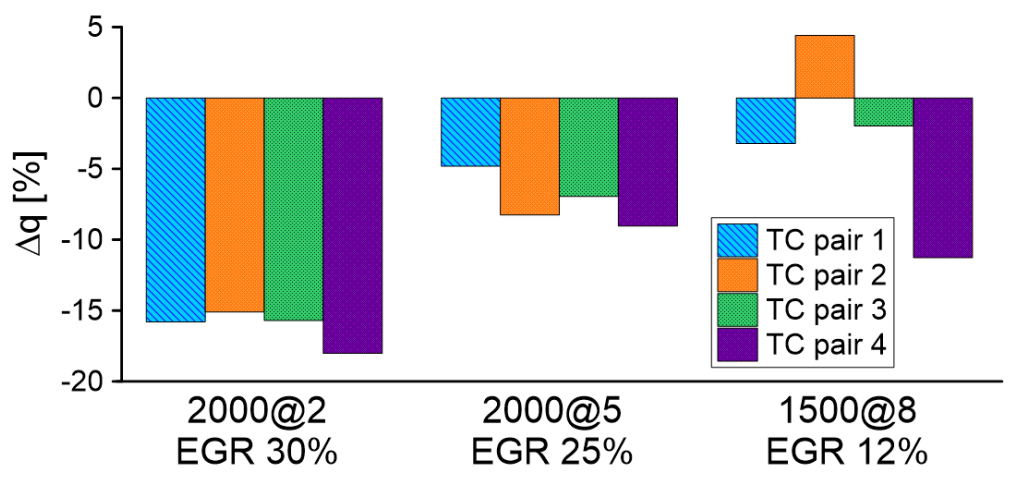

Figure 7: Effect of EGR on heat flux

EGR reduced heat flux. The maximum heat flux reduction was $18 \%$ in point $2000 @ 2$ with the highest EGR rate. Decrease of heat flux was on average $4 \%$ per every $10 \%$ increment of EGR rate. It can be inferred that the impact of EGR on those measurements was significant. The previous research reviewed in the Introduction reported diverging observations regarding the effect of EGR on heat transfer. It was under discussion whether EGR increased, reduced or had no significant influence on heat transfer. The present study indicates that EGR has a significant effect: reducing heat transfer in central areas of the firedeck. The literature mentions effects of EGR that contribute to reduce in-cylinder heat transfer. For instance, heat transfer near TDC can be reduced by the diminution of gas peak temperature and by the combustion shift [35]. In order to study the trends comprehensively, heat flux diminution was analyzed in $k \mathrm{Wm}^{-2}$ separating the different thermocouple pairs and including the intermediate level of EGR rate. The pairs of thermocouples are those of Figure 6. Heat flux per unit area was calculated with equation 1 and plotted in Figure 8. Swirl ratio was the minimum.

Some trends were close to being linear while others were not. They depended on the location and the operating point. Slopes were similar for 2000@5 and 2000@2 points at all locations. Thus, the effect of EGR on heat transfer showed low dependency on engine load. However, it must be taken into account that this conclusion is only valid 

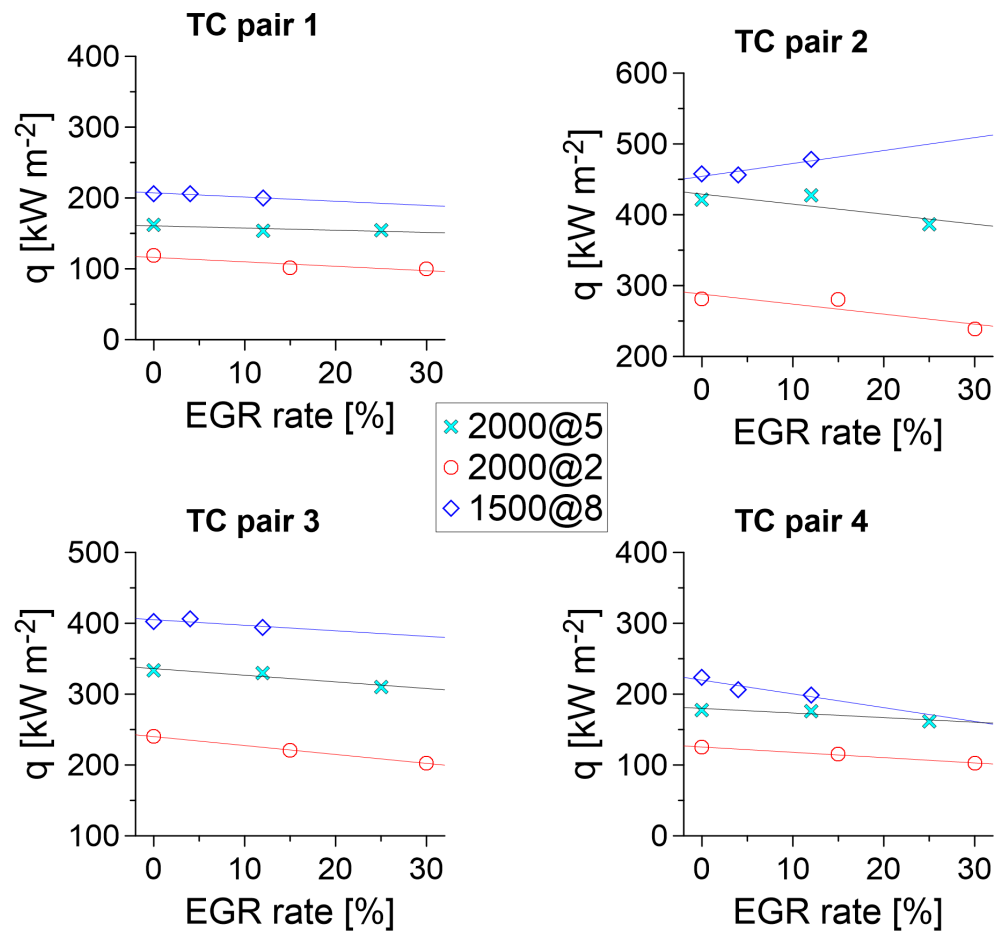

Figure 8: Heat flux density VS EGR rate

for the two examined low load points and cannot be extrapolated to other load levels.

In section 3.2, the heat flux uncertainty was determined. The uncertainty value was $9.6 \mathrm{kWm}^{-2}$. Next, the uncertainties of the heat flux values plotted in Figure 8 are given in Table 4 in percentage terms. Uncertainties ranged between $2 \%$ and $10 \%$. The thermocouple pair that presented the highest uncertainty was number 1 while the one with the lowest uncertainty was number 2 . It can be observed in Table 4 that the lower the heat flux, the higher the uncertainty was.

Lastly, local effects of EGR on heat transfer were visualized with distribution maps. Heat flux variation given by equation 4 was represented. Swirl ratio was the minimum.

$$
\Delta q_{i}=q_{i}\left(\mathrm{EGR}_{\max }\right)-q_{i}\left(\mathrm{EGR}_{\min }\right) \quad\left[k W m^{-2}\right]
$$

where $i$ is the operating point: $\mathrm{i}=2000 @ 5,2000 @ 2,1500 @ 8$.

In operating points 2000@5 and 2000@2, heat transfer decreased most in the central area, especially between the exhaust valves and the injector, as seen in Figures 9(a) and $9(\mathrm{~b})$. That is where EGR had the highest impact on heat transfer and it was also where heat flux was highest (see Figure 3). Operating point 1500@8 presented unclear trends of heat flux distribution. In particular, according to Figure 9(c), EGR discordantly increased or decreased heat flux at locations close to each other. This was consequence of the small variations of wall temperature caused by EGR in this operating point. 
Table 4: Heat flux uncertainty [\%].

\begin{tabular}{cccccc}
\hline & \multicolumn{9}{c}{ Thermocouple pair } & & \\
& EGR rate [\%] & 1 & 2 & 3 & 4 \\
\hline \multirow{3}{*}{$000 @ 2$} & 0 & 8.1 & 3.4 & 4 & 7.7 \\
& 15 & 9.5 & 3.4 & 4.4 & 8.3 \\
& 30 & 9.6 & 4 & 4.7 & 9.4 \\
\hline \multirow{3}{*}{$000 @ 5$} & 0 & 5.9 & 2.3 & 2.9 & 5.4 \\
& 12 & 6.3 & 2.2 & 2.9 & 5.5 \\
& 25 & 6.2 & 2.5 & 3.1 & 5.9 \\
\hline \multirow{3}{*}{$1500 @ 8$} & 0 & 4.7 & 2.1 & 2.4 & 4.3 \\
& 4 & 4.7 & 2.1 & 2.4 & 4.7 \\
& 12 & 4.8 & 2 & 2.4 & 4.8 \\
\hline
\end{tabular}

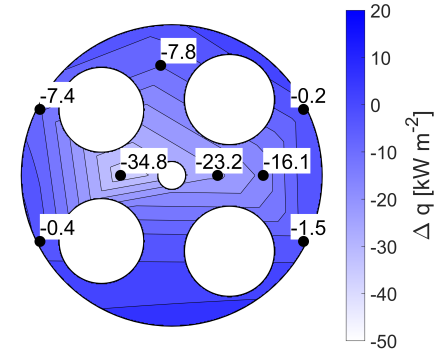

(a) 2000@5

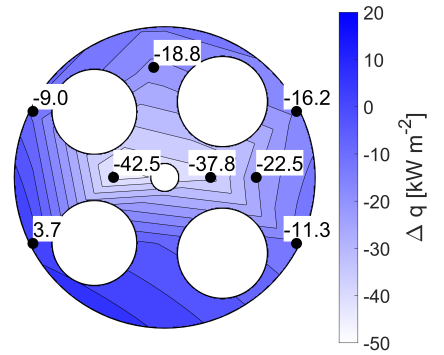

(b) 2000@2

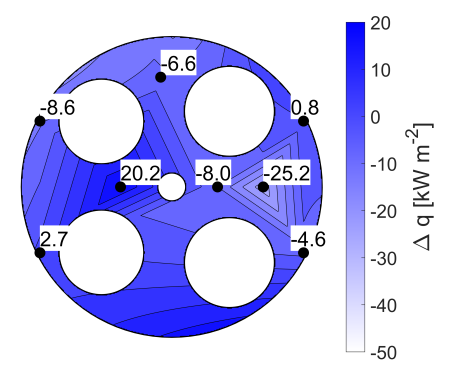

(c) 1500@8

Figure 9: Local distribution of the EGR effect on heat flux 


\subsection{Trade-off between emissions of nitrogen oxides and carbon dioxide}

Heat losses were found to decrease in some areas when EGR rates were increased. The reduction in heat transfer could help to reduce $\mathrm{CO}_{2}$ generation since it may improve indicated efficiency and thus lower fuel consumption. However, the recirculation of exhaust gas has other effects on the engine performance that can undermine efficiency. For instance, the reduced exhaust mass flow that passed through the turbine when the EGR valve was open led to an increase in pumping work and decrease in brake efficiency. Indeed, as can be seen in Figure 10, brake efficiency decreased or stayed constant with higher EGR rates. Ultimately it is the brake efficiency that drives the vehicle and determines fuel consumption and $\mathrm{CO}_{2}$ production. Since the reason to use EGR is to diminish $\mathrm{NO}_{x}$ emissions, a comparison between the benefit obtained in $\mathrm{NO}_{x}$ and the variation of $\mathrm{CO}_{2}$ is suitable to complete the evaluation of the EGR influence in heat transfer. In Figure 11, the mass flow of $\mathrm{CO}_{2}$ at the exhaust was plotted on the $\mathrm{x}$-axis and the mass flow of $\mathrm{NO}_{x}$ on the $\mathrm{y}$-axis. Operating point and EGR rate are indicated by the labels inside Figure 11. It can be observed that, in general, $\mathrm{CO}_{2}$ increased with EGR but $\mathrm{NO}_{x}$ diminution was more substantial than increase in $\mathrm{CO}_{2}$. In particular, for every additional unit of EGR rate, $\mathrm{NO}_{x}$ percentage reduction was approximately ten times greater than $\mathrm{CO}_{2}$ percentage increment.

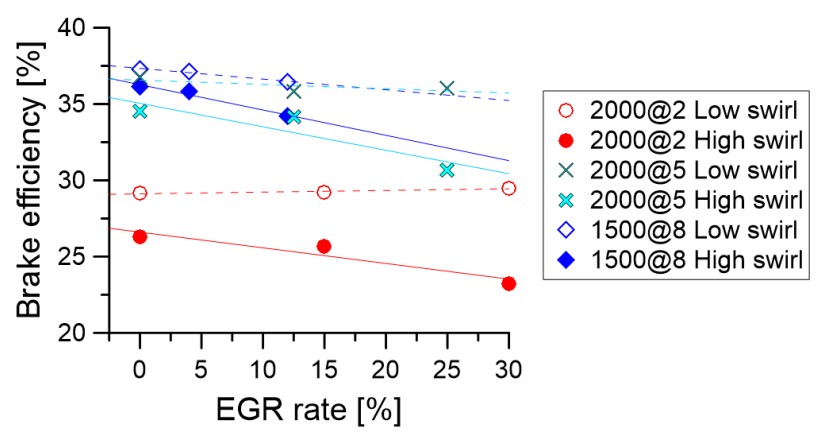

Figure 10: Brake efficiency VS EGR rate

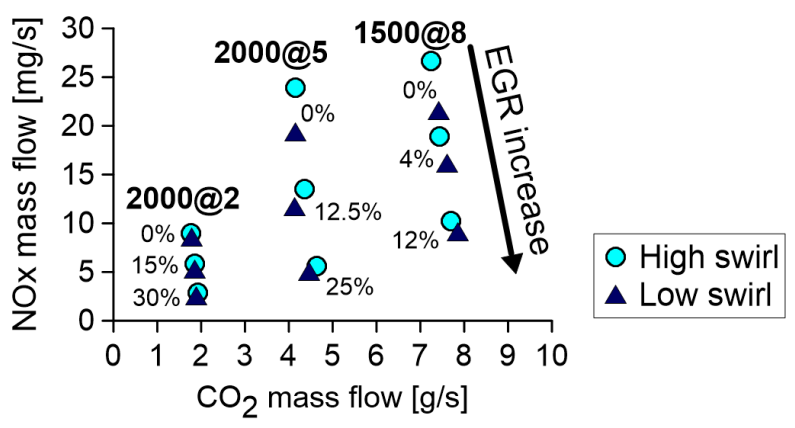

Figure 11: $\mathrm{NO}_{x}$ and $\mathrm{CO}_{2}$ emissions 


\section{Conclusions}

Influence of EGR on heat transfer was investigated experimentally. The measurement technique consisted on thermocouples inserted in the metallic wall of the firedeck at distances of $4 \mathrm{~mm}$ and $7 \mathrm{~mm}$ from the surface. Axial heat flux by conduction was calculated from the measured temperatures. Since there were 17 thermocouples located in different areas of the firedeck, local effects were assessed. Engine tests included three operating points, three levels of EGR rate and two levels of swirl ratio. Studies were made concerning the influence of EGR on wall temperatures, the significance of EGR for heat transfer, its dependency on load and engine speed and the spatial distribution of the effect. Lastly, the influence of high pressure EGR on both $\mathrm{NO}_{x}$ and $\mathrm{CO}_{2}$ emissions was evaluated in all operating conditions under study. The obtained conclusions were valid for engines with high pressure EGR systems. However, since intake conditions were controlled (gas composition and temperature), the observed effect of EGR on heat transfer is expected to be also applicable to engines with low pressure EGR.

- EGR showed a significant influence on firedeck temperatures and on heat flux. This finding differs from some reports in the literature which found no significant effect of EGR on those variables.

- The effect of EGR was to reduce wall temperatures and heat flux. This is relevant because diverging trends had been mentioned in the literature.

- The area where heat flux presented the most significant variations was the center of the firedeck. The biggest reduction of heat flux observed locally was $18 \%$ with an EGR rate of $30 \%$.

- In general, EGR increased $\mathrm{CO}_{2}$ emissions, but the percentage reduction of $\mathrm{NO}_{x}$ emissions was approximately ten times greater than the percentage increase in $\mathrm{CO}_{2}$ emissions for each unit of EGR rate.

\section{Acknowledgments}

The authors acknowledge General Motors Global R\&D for supporting this research. The equipment used in this work was partially supported by FEDER project funds "Dotación de infraestructuras científico técnicas para el Centro Integral de Mejora Energética y Medioambiental de Sistemas de Transporte (CiMeT), (FEDER-ICTS2012-06)", framed in the operational program of unique scientific and technical infrastructure of the Ministry of Science and Innovation of Spain. Josep Salvador-Iborra was partially supported through contract FPI-S2-2016-1357 of "Programa de Apoyo para la Investigación y Desarrollo (PAID-01-16)" of Universitat Politècnica de València.

\section{References}

\section{References}

[1] J. Benajes, A. García, J. Monsalve-Serrano, V. Boronat, Achieving clean and efficient engine operation up to full load by combining optimized RCCI and dualfuel diesel-gasoline combustion strategies, Energy Conversion and Management 136 (2017) 142-151. doi:10.1016/j.enconman.2017.01.010. 
[2] A. A. Abdel-Rahman, On the emissions from internal-combustion engines: a review, Int. J. Energy Res. 22 (6) (1998) 483-513. doi:10.1002/(SICI)1099114X(199805)22:6 483::AID-ER377 3.0.CO;2-Z.

[3] E. Svensson, T. Berntsson, Economy and CO2 emissions trade-off: A systematic approach for optimizing investments in process integration measures under uncertainty, Applied Thermal Engineering 30 (1) (2010) 23-29. doi:10.1016/j.applthermaleng.2009.02.010.

[4] B. Chu, S. Duncan, A. Papachristodoulou, C. Hepburn, Analysis and control design of sustainable policies for greenhouse gas emissions, Applied Thermal Engineering 53 (2) (2013) 420-431. doi:10.1016/j.applthermaleng.2012.04.022.

[5] V. Y. Prikhodko, J. E. Parks, J. A. Pihl, T. J. Toops, Passive SCR for lean gasoline NOx control: Engine-based strategies to minimize fuel penalty associated with catalytic NH3 generation, Catal. Today 267 (2016) 202-209. doi:10.1016/j.cattod.2016.01.026.

[6] G. Borman, K. Nishiwaki, Internal-combustion engine heat transfer, Progress in Energy and Combustion Science 13 (1) (1987) 1-46. doi:10.1016/03601285(87)90005-0.

[7] J. M. Luján, C. Guardiola, B. Pla, A. Reig, Switching strategy between HP (high pressure)- and LPEGR (low pressure exhaust gas recirculation) systems for reduced fuel consumption and emissions, Energy 90 (2015) 1790-1798. doi:10.1016/j.energy.2015.06.138.

[8] A. Chaloulakou, I. Mavroidis, I. Gavriil, Compliance with the annual NO2 air quality standard in Athens. Required NOx levels and expected health implications, Atmos. Environ. 42 (3) (2008) 454-465. doi:10.1016/j.atmosenv.2007.09.067.

[9] H. Zhou, M. Zhou, Z. Liu, M. Cheng, J. Chen, Modeling NOx emission of coke combustion in iron ore sintering process and its experimental validation, Fuel 179 (2016) 322-331. doi:10.1016/j.fuel.2016.03.098.

[10] S. Ogunwumi, R. Fox, M. D. Patil, L. He, In-Situ NH 3 Generation for SCR NOx Applications, SAE 2002-01-28. doi:10.4271/2002-01-2872.

[11] W. Li, Z. Liu, Z. Wang, Y. Xu, Experimental investigation of the thermal and diluent effects of EGR components on combustion and NOx emissions of a turbocharged natural gas SI engine, Energy Conversion and Management 88 (2014) 1041-1050. doi:10.1016/j.enconman.2014.09.051.

[12] N. Ladommatos, S. M. Abdelhalim, H. Zhao, Z. Hu, The Dilution, Chemical, and Thermal Effects of Exhaust Gas Recirculation on Diesel Engine Emissions - Part 2: Effects of Carbon Dioxide, in: SAE 961167, 1996. doi:10.4271/961167.

[13] V. Bermúdez, J. M. Luján, B. Pla, W. G. Linares, Effects of low pressure exhaust gas recirculation on regulated and unregulated gaseous emissions during NEDC in a light-duty diesel engine, Energy 36 (9) (2011) 5655-5665. doi:10.1016/j.energy.2011.06.061.

[14] N. Ladommatos, S. M. Abdelhalim, H. Zhao, Z. Hu, The Dilution, Chemical, and Thermal Effects of Exhaust Gas Recirculation on Diesel Engine Emissions - Part 1: Effect of Reducing Inlet Charge Oxygen, in: SAE 961165, 1996. doi:10.4271/961165. 
[15] T. Jacobs, D. N. Assanis, Z. Filipi, The Impact of Exhaust Gas Recirculation on Performance and Emissions of a Heavy-Duty Diesel Engine, in: SAE 2003-011068, 2003. doi:10.4271/2003-01-1068.

[16] M. Zheng, G. T. Reader, J. G. Hawley, Diesel engine exhaust gas recirculation a review on advanced and novel concepts, Energy Convers. Manag. 45 (2004) 883-900. doi:10.1016/S0196-8904(03)00194-8.

[17] F. Xie, W. Hong, Y. Su, M. Zhang, B. Jiang, Effect of external hot EGR dilution on combustion, performance and particulate emissions of a GDI engine, Energy Conversion and Management 142 (2017) 69-81. doi:10.1016/j.enconman.2017.03.045.

[18] G. Abd-Alla, G. Abdalla, Using exhaust gas recirculation in internal combustion engines: a review, Energy Convers. Manag. 43 (8) (2002) 1027-1042. doi:10.1016/S0196-8904(01)00091-7.

[19] D. Agarwal, S. K. Singh, A. K. Agarwal, Effect of Exhaust Gas Recirculation (EGR) on performance, emissions, deposits and durability of a constant speed compression ignition engine, Appl. Energy 88 (8) (2011) 2900-2907. doi:10.1016/j.apenergy.2011.01.066.

[20] N. Ladommatos, S. M. Abdelhalim, H. Zhao, Z. Hu, The Dilution, Chemical, and Thermal Effects of Exhaust Gas Recirculation on Diesel Engine Emissions - Part 4: Effects of Carbon Dioxide and Water Vapour, in: SAE 971660, 1997. doi:10.4271/971660.

[21] N. Ladommatos, S. Abdelhalim, H. Zhao, The effects of exhaust gas recirculation on diesel combustion and emissions, Int. J. Engine Res. 1 (1) (2000) 107-126. doi:10.1243/1468087001545290.

[22] T. W. Ryan, T. J. Callahan, Homogeneous Charge Compression Ignition of Diesel Fuel, in: SAE 961160, 1996. doi:10.4271/961160.

[23] S. Kimura, O. Aoki, Y. Kitahara, E. Aiyoshizawa, Ultra-Clean Combustion Technology Combining a Low-Temperature and Premixed Combustion Concept for Meeting Future Emission Standards, in: SAE 2001-01-0200, 2001. doi:10.4271/2001-01-0200.

[24] S. Lee, M. A. Gonzalez D., R. D. Reitz, Stoichiometric Combustion in a HSDI Diesel Engine to Allow Use of a Three-way Exhaust Catalyst, in: SAE 2006-011148, 2006. doi:10.4271/2006-01-1148.

[25] X. Tauzia, A. Maiboom, Experimental study of an automotive Diesel engine efficiency when running under stoichiometric conditions, Appl. Energy 105 (2013) 116-124. doi:10.1016/j.apenergy.2012.12.034.

[26] K. Akihama, Y. Takatori, K. Inagaki, S. Sasaki, A. M. Dean, Mechanism of the Smokeless Rich Diesel Combustion by Reducing Temperature, in: SAE 2001-010655, 2001. doi:10.4271/2001-01-0655.

[27] C. A. Idicheria, L. M. Pickett, Soot Formation in Diesel Combustion under High-EGR Conditions, in: SAE Technical Paper, SAE International, 2005. doi:10.4271/2005-01-3834.

[28] A. García, J. Monsalve-Serrano, V. R. Roso, M. E. S. Martins, Evaluating the emissions and performance of two dual-mode RCCI combustion strategies under the World Harmonized Vehicle Cycle (WHVC), Energy Conversion and Management 149 (2017) 263 - 274. doi:10.1016/j.enconman.2017.07.034. 
[29] C. Finol Parra, Heat transfer investigations in a modern diesel engine, Ph.D. thesis (2008).

[30] J. A. Caton, Heat Transfer Characteristics of Conventional and High Efficiency IC Engines Using External or Internal Exhaust Gas Dilution, in: Vol. 1, ASME 2015 Internal Combustion Engine Division Fall Technical Conference, 2015, pp. Paper No. ICEF2015-1012, pp. V001T03A002. doi:10.1115/ICEF2015-1012.

[31] P. Olmeda, J. Martín, A. García, D. Blanco, Evaluation of EGR Effect on the Global Energy Balance of a High Speed DI Diesel Engine, SAE 2016-01-06. doi:10.4271/2016-01-0646.

[32] F. Payri, P. Olmeda, J. Martín, A. García, A complete 0D thermodynamic predictive model for direct injection diesel engines, Applied Energy 88 (12) (2011) 4632-4641. doi:10.1016/j.apenergy.2011.06.005.

[33] A. J. Torregrosa, P. Olmeda, J. Martín, C. Romero, A Tool for Predicting the Thermal Performance of a Diesel Engine, Heat Transfer Engineering 32 (10) (2011) 891-904. doi:10.1080/01457632.2011.548639.

[34] F. P. Incropera, D. P. DeWitt, T. L. Bergman, A. S. Lavine, Fundamentals of Heat and Mass Transfer, Vol. 6th of Dekker Mechanical Engineering, John Wiley \& Sons, 2007.

[35] N. Ladommatos, S. M. Abdelhalim, H. Zhao, Z. Hu, Effects of EGR on Heat Release in Diesel Combustion, SAE no. 980184.doi:10.4271/980184. 